\title{
Durability Studies of Self-Compacting Concrete containing Electric Arc- Furnace Slag Aggregate
}

\author{
Amaia Santamaria ${ }^{1}$, Marta Skaf ${ }^{2}$, Vanesa Ortega-Lopez ${ }^{3}$, Estibaliz Briz ${ }^{4}$, José T. San \\ José $^{5}$ and Javier J. González ${ }^{6}$
}

${ }^{1}$ Inter Department of Mechanical Engineering, University of the Basque Country UPV/EHU. Paseo Rafael Moreno Pitxitxi 2 - 48013 Bilbao, Spain amaia.santamaria@ehu.eus

2 Department of Construction, University of Burgos UBU. Calle Villadiego, s/n - 09001 Burgos, Spain mskaf@ubu.es

3 Department of Civil Engineering, University of Burgos UBU. Calle Villadiego, s/n - 09001 Burgos, Spain vortega@ubu.es

4 Department of Mechanical Engineering, University of the Basque Country UPV/EHU. Paseo Rafael Moreno Pitxitxi 2 - 48013 Bilbao, Spain estibaliz.briz@ehu.eus

5 Department of Metallurgical Engineering and Materials Science, University of the Basque Country UPV/EHU. Plaza Ingeniero Torres Quevedo, 1 - 48013 Bilbao, Spain josetomas.sanjose@ehu.eus

6 Department of Metallurgical Engineering and Materials Science, University of the Basque Country UPV/EHU. Plaza Ingeniero Torres Quevedo, 1 - 48013 Bilbao, Spain javierjesus.gonzalez@ehu.eus

\begin{abstract}
The structure of self-compacting concretes containing electric arc-furnace slag, their mechanical behavior, and their durability are all studied in an extensive experimental campaign, to evaluate the suitability of three concrete mixes for use in real construction works. Specimens manufactured with self-compacting electric arc-furnace slag concrete are subjected to wetting-drying and freezing-thawing test procedures, for their study in aggressive environments, especially marine environments. In general, all the test results were quite encouraging. It was once again demonstrated that the use of electric arc-furnace slag in concrete represents an opportunity to reduce both the volume of siderurgical waste generated in our society, and the consumption of fresh raw materials.
\end{abstract}

Keywords: Self-Compacting Concrete, Electric Arc-Furnace Slag, Durability, Marine Environment.

\section{Introduction}

The future of the environment is a source of growing concern in present-day society that is calling for increasingly sustainable development. The sustainability of production processes must be carefully studied and waste-streams must wherever possible be reutilized and recycled. However, waste reduction also implies the manufacture of products of greater durability. Sustainable production processes are already dynamizing the circular economy while maintaining relevant standards and properties. Concrete products that reuse waste must therefore at the very least equal those of conventional Portland mixes.

This study is focused on the reuse of Electric Arc-furnace Slag (EAFS), a residue from the steelmaking industry, as aggregate in concrete mixtures. The reuse of slag in cement-based 
material has been a recurrent topic since Motz, Geiseler and Koros (Geiseler, 1996; Koros, 2003; Motz and Geiseler, 2001) published the first studies on the reuse of slag in the construction industry.

Since those first initial studies, the mechanical behavior and the hardened properties of concretes manufactured with EAFS as aggregate have been evaluated in several studies (AbuEishah, El-Dieb, and Bedir, 2012; Faleschini et al., 2015; Manso, Gonzalez, and Polanco, 2004). Studies have also been performed on the durability of those types of concretes (Arribas, Vegas, San-José, and Manso, 2014; Manso, Polanco, Losañez, and González, 2006). In general, most of the tests on their mechanical behavior and durability have demonstrated that EAF concretes can at least equal the behavior of natural aggregate concrete.

In some of the above works, poorer workability than natural concrete aggregate has been identified as a disadvantage of EAFS concrete. In this work it will be demonstrated that with the correct mix design, self-compacting concrete can be made using EAFS as aggregate. Its durability will also be evaluated, lending special attention to the durability of EAFS selfcompacting concretes in highly saline marine environments.

There are two principal reasons for this study: on the one hand, there are few studies on the evaluation of the behavior of EAFS concrete in marine environments and, on the other hand, the mechanical and the physical characteristics of EAFS concrete point to its suitability for the construction of dykes and blocks to form protective seawalls. In fact, work is underway with this type of concrete for that same purpose in coastal areas of the Basque Country, a region of northern Spain, where the evaluation of the durability of EAFS concrete in marine environments assumes special importar furnace slag concrete in

2 Materials and
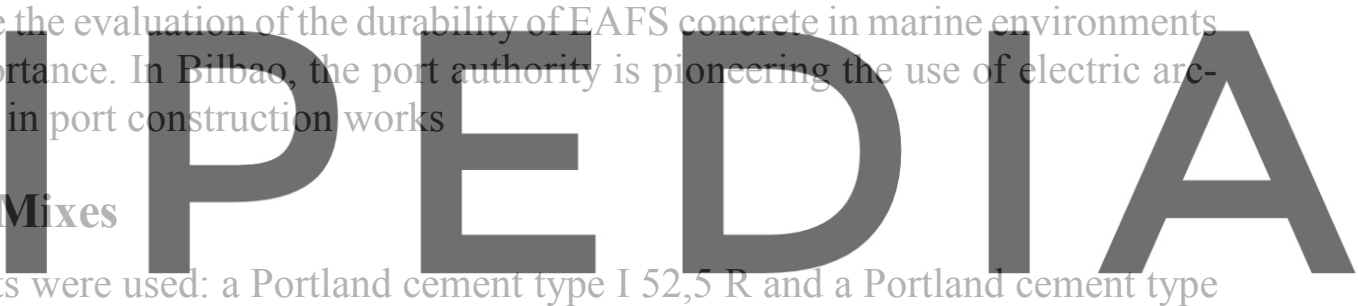

Two different cements were used: a Portland cement type I 52,5
IV/B-V 32.5N, which included fly ash, as per standard EN 197-1

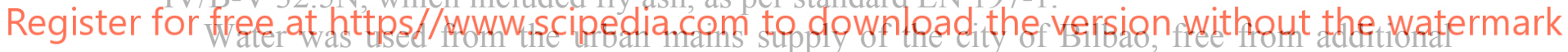

particles that might adversely affect the mixes.

The commercial limestone aggregate was of three different sizes $0-1,0-5$, and 5-12. Likewise, the Electric Arc-furnace Slag (EAFS) had aggregate fractions of 0-4 and 4-12. Finally, a superplasticizer supplied by CHRYSO was selected to adjust the workability of the mix.

Three different mixes designs, shown in Table 1, were prepared with these materials:

$>$ A reference mix, labeled NATI, manufactured with Portland cement type I and limestone aggregates,

$>$ A mix labeled EAFSI, in which Portland cement-type I was used, although unlike in the reference mix, EAFS was used in partial substitution by volume of the limestone aggregates. Nevertheless, proportional amounts of the different aggregate fractions were not exactly the same. The higher density and the rougher surface of the EAFS particles require higher proportions of fines, to manufacture mixes with this type of aggregate (Santamaría et al., 2017).

$>$ An EAFSIV mix, with exactly the same design as the EAFSI mix, except that Portland cement-type IV, rather than Portland cement-type I, was used. 
Table 1. Mix design.

\begin{tabular}{cccc}
\hline & NAT I & EAFSI & EAFSIV \\
\hline Cement I & 330 & 330 & \\
\hline Cement IV & & & 330 \\
\hline Water & 165 & 165 & 165 \\
\hline EAFS 4-12 & & 760 & 760 \\
\hline EAFS 0-4 & & 550 & 550 \\
\hline Limestone fines 0-1,2 & 690 & 900 & 900 \\
\hline Limestone 0-5 & 560 & & \\
\hline Limestone 5-12 & 730 & & \\
\hline Superplasticizer & $2 \%$ & $2 \%$ & 2.58 \\
\hline cement weight) & & & \\
\hline Density (t/m $\left.{ }^{3}\right)$ & 2.41 & 2.69 & 1 \\
\hline Slump flow spread. & 630 & 680 & \\
\hline Abrams Cone (mm) & & & \\
\hline L-box & 1 & 1 & \\
\hline
\end{tabular}

The NATI mix was molds. An industrial co the manufacture of EAFSI and mix and several molds evaluated.
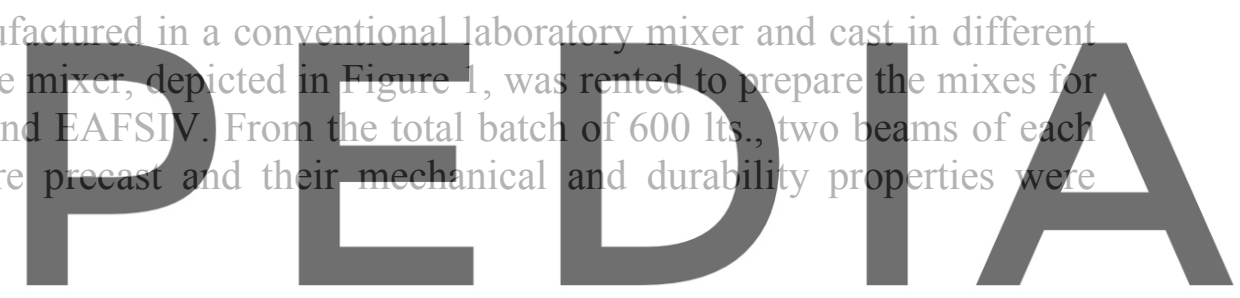

Register for free at https//www.scipedia.com to download the version without the watermark

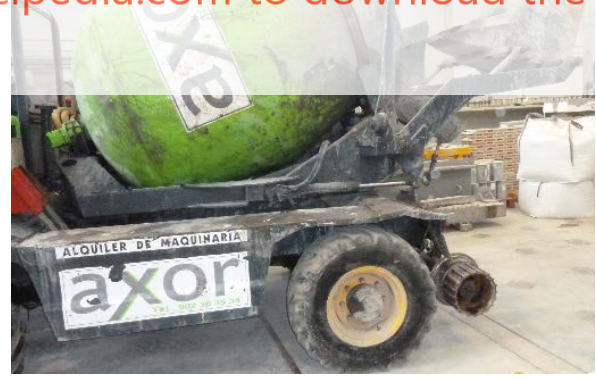

Figure 1. Concrete mixer.

\section{Test Method}

Two tests were used to evaluate the workability of the mixes, a slump flow cone in accordance with ASTM C1611 and the L-box test, in accordance with the EFNARC standard.

The bulk density of the mixes was measured as specified in the EN 1015-10 standard. The compressive strength of the mixes was evaluated at 7, 28, 90 and 180 days, as recommended in EN-12390-3. 
The Fagerlund test described in the UNE 83982 standard, based on Darcy's law, was used to analyze water absorption by capillarity.

Mix durability was evaluated with wetting-drying and freezing-thawing tests. Both tests were performed on 2 different specimens of each mix, after 90 days of curing. 148 cycles were performed for each wetting-drying test. Each cycle involved leaving each specimen in water for 16 hours, in an oven at $60^{\circ} \mathrm{C}$ for 6 hours placed, and at room temperature for 2 hours, to prevent thermal shock. The freezing-thawing test involved 122 cycles, in which the specimens were kept in a freezer at $-15^{\circ} \mathrm{C}$ for 24 hours and in water, at room temperature, over the following 24 hours. The mechanical properties of the specimens were evaluated both before and after the durability test.

Three batches of specimens $\left(100 \times 100 \times 100 \mathrm{~mm}^{3}\right)$ of each mix, as shown in Figure 2, were enclosed in cages suspended from a dock wall in Pasaia Donibane port, with the purpose of analyzing EAFS concrete durability in marine environments. The cages were suspended in an intertidal zone where they would be submerged under the seawater at high tide and exposed to the atmosphere at low tide. The specimens were left in the cages for one year. After their removal, chlorine and sulphate ion infiltration was evaluated, by cutting each specimen and placing it in a vacuum chamber that was filled with nitrogen at low pressure for Scanning Electron Microscopy (SEM) analysis. Energy-dispersive X-ray spectroscopy was used to obtain the chemical composition of the first $50 \mathrm{~mm}$ of the fracture surface and to generate backscattered electron images.
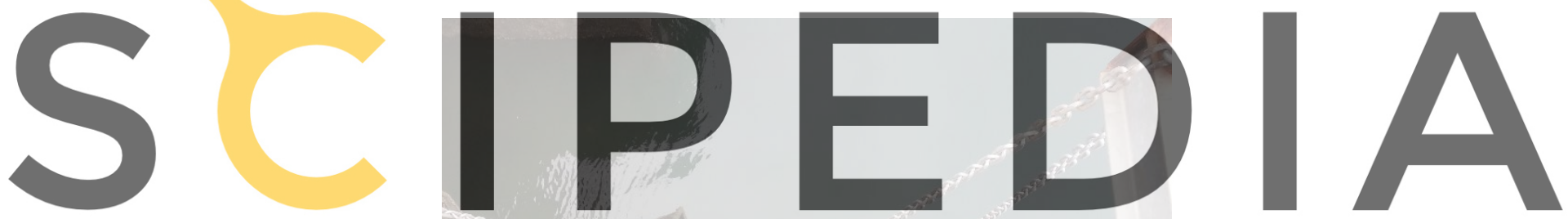

Register for free at https//www.scipedia.com to download the version without the watermark

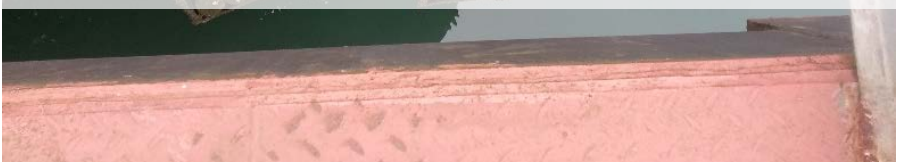

Figure 2. Specimens placed in cages at Pasaia Port.

\section{Results}

\subsection{Workability}

The workability test results of the mixes are shown in Table 1. All the mixes could be classified as self-compacting mixes. The reference mix had a lower spread than the EAFS aggregate mixes, which was a somewhat surprising result, thought to be due to the different scale of the mixes. A large number of laboratory trials had been performed before manufacturing the 600 1t. of concrete used in the mixes. The workability of the mixes with the same dosages manufactured on a small scale was worse than in the larger mixes, due in all likelihood to the 
skin effect. Nevertheless, such a slight difference in workability was marginal for the purposes of this research, alongside the key aspect: the self-compacting properties of the mixes.

\subsection{Density and Mechanical Strength}

As might be expected, the density of the concretes manufactured with EAFS was higher than the density of the concrete manufacture with natural aggregates, with increases of around $11 \%$ in the case of EAFSI and 7\% in the case of EAFSIV.

Concrete strength over time is depicted in Figure 3. The behaviors of both concretes manufactured with Portland cement type I were very similar. The EAFSI mixes gained slightly higher strengths, compensating their higher density than the other mixes. The higher strength of EAFS concretes has been explained in a previous paper (Arribas, Santamaría, Ruiz, OrtegaLópez, and Manso, 2015), by the denser aggregate and cement-paste interface.

The hardened strength of EAFSIV was lower than its EAFSI counterpart, reflecting the characteristics of the Portland cement type IV.
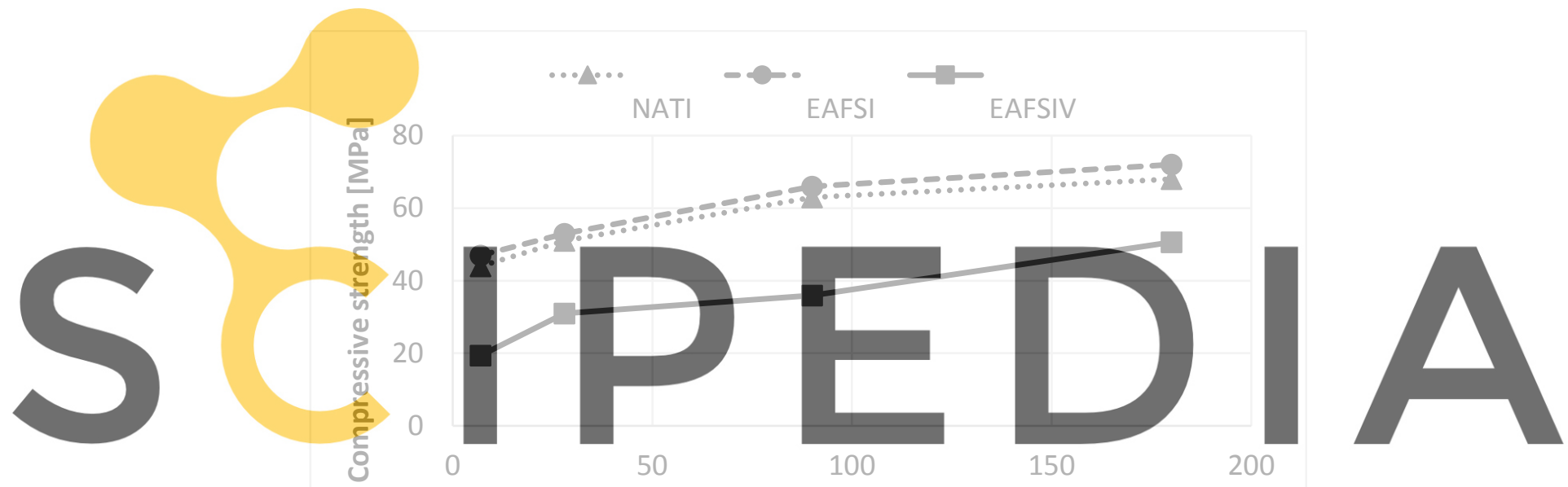

Register for free at https//www.scipedia.com to dovinload the version without the watermark

Figure 3. Compressive strength.

\subsection{Capillarity Water Absorbtion}

The results obtained in the capillarity water test are shown in Figure 4. The results for NATI and EAFSI were similar, unlike for EAFSIV. The curves can be divided into two zones: an initial rising zone; and, a second zone, where capillarity porosity was not evaluated as it involved other types of porosities. The less inclined slope ( $\mathrm{K}$ coefficient $0,106 \mathrm{~kg} / \mathrm{m}^{2} \mathrm{~s}^{1 / 2}$ ) of the EAFSIV, in the first zone, represents low permeability. The value of the second zone shows us that the total porosity of the mix was high, which means that this mix may have a high number of single, unconnected spherical pores, which could also explain the lower density of the mix in comparison with the EAFSI mix. Both for NATI and for EAFSI, the slope of the curve was the same in the first zone ( $\mathrm{K}$ coefficient $0,156 \mathrm{~kg} / \mathrm{m}^{2} \mathrm{~s}^{1 / 2}$ ), so the capillarity porosity was similar in both mixes, in the second zone, mix EAFSI achieved higher values, which might be explained by the higher porosity of the EAFS aggregate when compared with the limestone aggregate. 


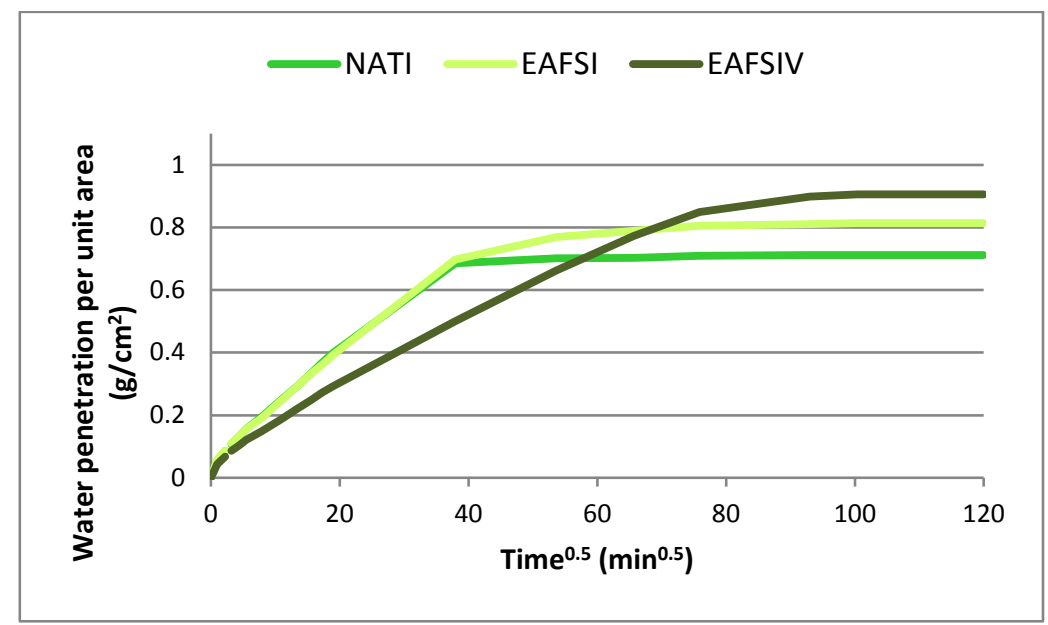

Figure 4. Capillarity test results.

\subsection{Wetting-Drying and Freezing-Thawing Tests}

The variation of the mechanical properties and weight of the mixes after performing durability tests are shown in Table 2. The mechanical properties of mixes NATI and EAFSI achieved similar levels. The mass loss of the EAFSI mix was higher than the mass loss of mix NATI, although if we take into account the different densities of both mixes, then their loss of volume

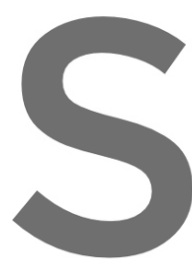
was similar.

The behavior of mix mixes NATI and EAFS aggressive cycles. Resul term pozzolanic reactions.
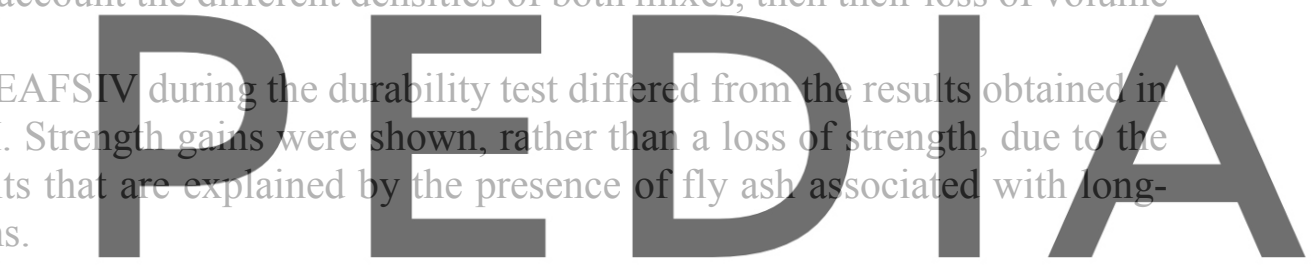

Table 2. Results of wetting-drying and freezing-thawing tests.

Register for free at https//WwW.scipedia.com to download the version without the watermark

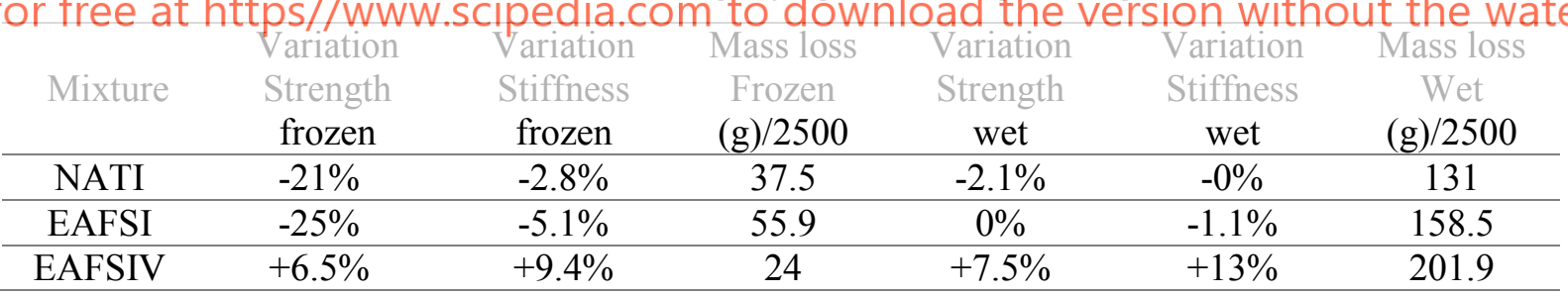

\subsection{Marine Environment Test}

In Figure 5, it is possible to see the specimens before and after exposure to a highly saline marine environment after one year. It would appear, a priori, that this concrete has no compounds that could harm the marine ecosystem, as the specimens were teaming with mussels, oysters, and small crabs.

The behavior of EAFS concrete in marine environments was good, and even better than the behavior of natural aggregate concretes, showing slightly better strengths. The results of the analysis are in the Figure 6. No data on sulfate ions are included, as no ions of that type were found. 


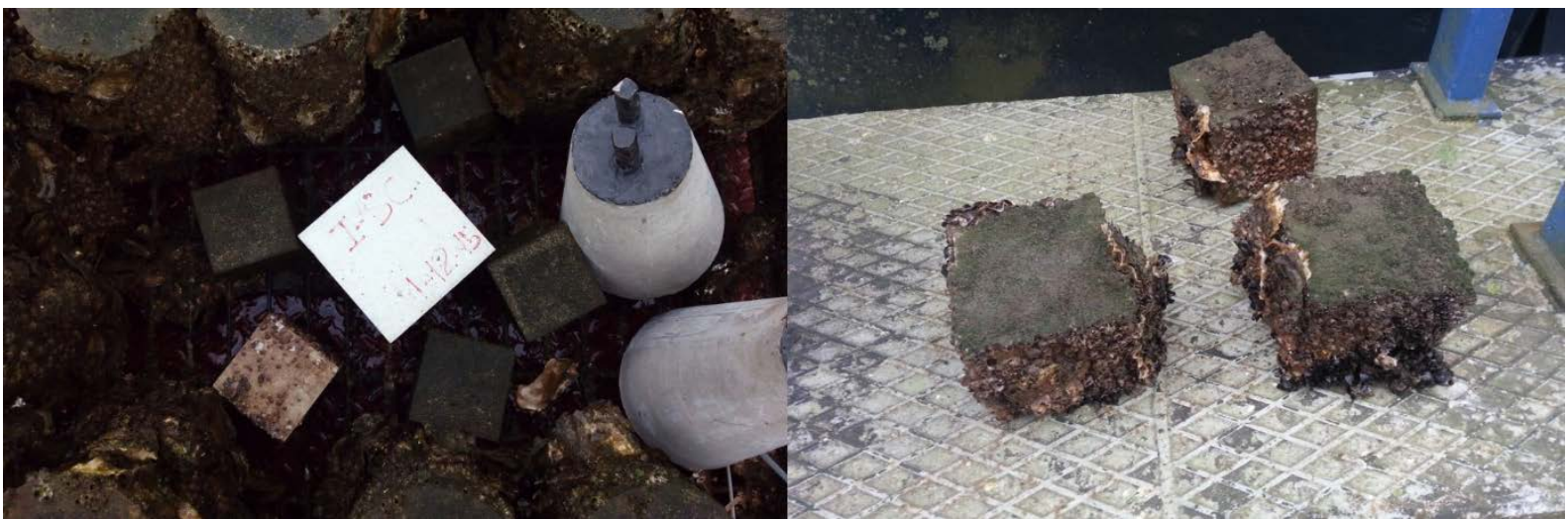

Figure 5. Specimens before and after the marine environment test.

Taking into account that $0.1 \%$ is a typical chlorine ion content of a cement paste, chlorineion penetration was around $35 \mathrm{~mm}$ in NATI, and approximately $25 \mathrm{~mm}$ and $15 \mathrm{~mm}$, in EAFSI and in EAFSIV, respectively. The higher resistance of EAFSIV to chlorine-ion penetration can be explained by looking at the results of the capillarity water test.
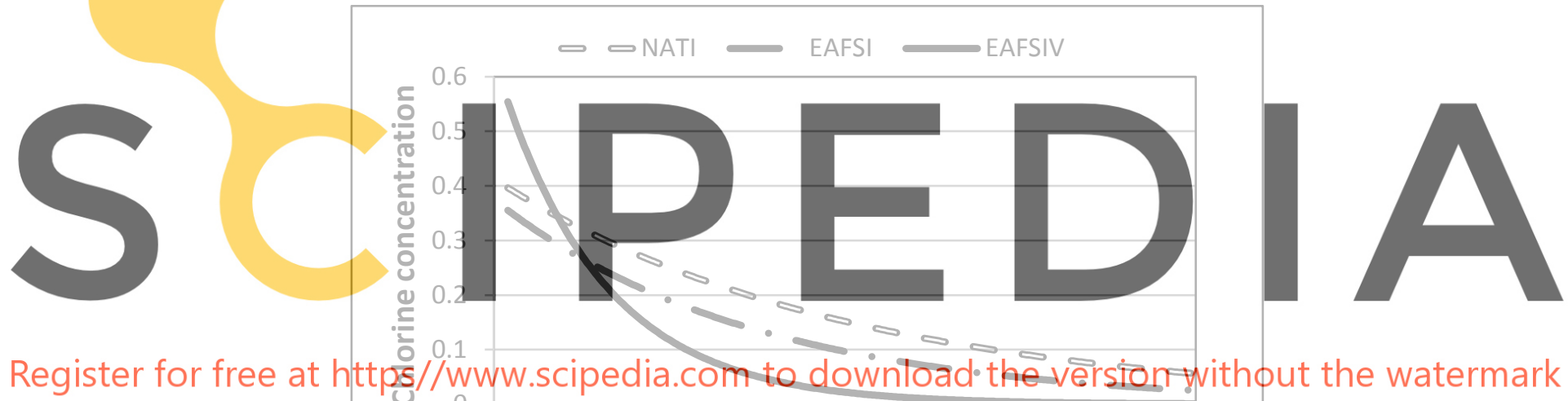

Register for free at https

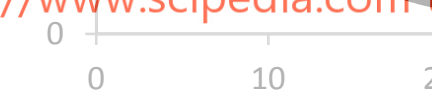

\section{Depth [mm]}

Figure 6. Specimens before and after the marine environment test.

\section{Conclusion}

Following the research campaign tests developed for this study, the following conclusions have been drawn:

- Mixes containing EAFS aggregate may be manufactured to the required workability, using the correct mix design. Self-compacting mixes have been successfully manufactured

- Both the mechanical behavior and the structure of the mixes manufactured with electric arc-furnace slag were fairly similar to the behavior and the structure of the mixes manufactured with natural aggregates. The main differences were observed when a different type of cement was used, in addition to the observably lower mechanical 
strengths, as may be expected, in the cement type IV mixes, which also had different pore structures with larger pore volumes.

- The use of electric arc-furnace slag as a concrete aggregate was not detrimental to the durability of the concrete. The great similarities with no major differences between the natural and the EAFS aggregates were confirmed by the test results.

\section{Acknowledgements}

The authors wish to express their gratitude to the following institutions: the Spanish Ministry (MICINN) and FEDER (European Regional Development Funds) through contract RTI2018-097079-B-C31 (MCIU/AEI/FEDER, UE); the Basque Government research group (IT1314-19), and the UPV/EHU [PPGA19/029. Our thanks also go to the Vice-Rectorate of Investigation of the University of Burgos [SUCONS] and to the Junta de Castilla y León (Regional Government) for funding the UIC-231 group through project BU119P17 partially supported by FEDER funds Finally, our thanks likewise to HORMOR Zestoa for supplying the steelmaking slags and to the University of Burgos (EPS -LaMilanera) for their support at several experimental stages.

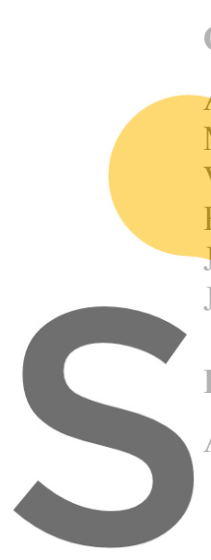

ORCID

Amaia Santamaria: https://orcid.org/0000-0002-4559-8734

Marta Skaf: https://orcid.org/0000-0001-7205-2692

Vanesa Ortega-Lopez: https://orcid.org/0000-0003-0212-355X

Estibaliz Briz: https://orcid.org/0000-0003-3933-3585

José Tomás San José: https://orcid.org/0000-0003-4904-6731

Javier Jesús González: https://orcid. org/0000-0002-0932-7937

References

Abu-Eishah, S. I., El-Diel,

(EAF) steel slag aggre

256. doi:http://dx.doi.or

Arribas, 1, Santamaría, A

use in hydraulic
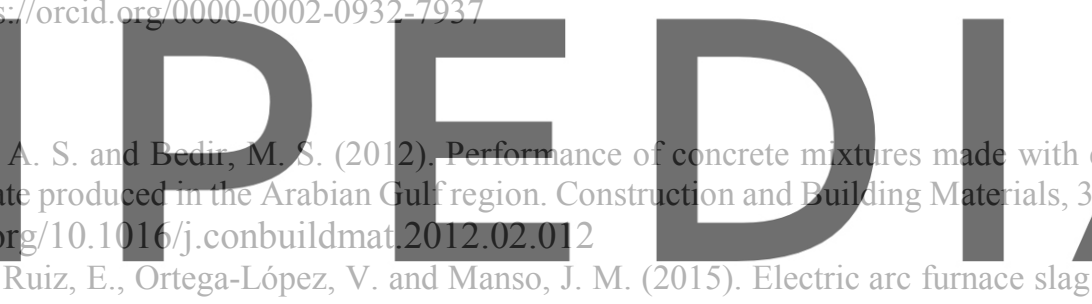

concrete.

Construction

and Building 90

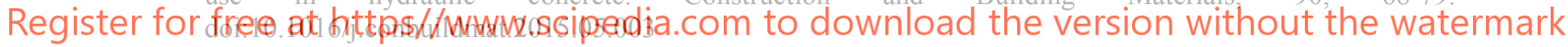

Arribas, I., Vegas, I., San-José, J. T. and Manso, J. M. (2014). Durability studies on steelmaking slag concretes. Materials \& Design, 63, 168-176. doi:http://dx.doi.org/10.1016/j.matdes.2014.06.002

Faleschini, F., Alejandro Fernández-Ruíz, M., Zanini, M. A., Brunelli, K., Pellegrino, C. and Hernández-Montes, E. (2015). High performance concrete with electric arc furnace slag as aggregate: Mechanical and durability properties. Construction and Building Materials, 101, 113-121. doi:10.1016/j.conbuildmat.2015.10.022

Geiseler, J. (1996). Use of steelworks slag in Europe doi:http://dx.doi.org/10.1016/S0956-053X(96)00070-0

Koros, P. J. (2003). Dusts, scale, slags, sludges... not wastes, but sources of profits. Metallurgical and Materials Transactions B, 34(6), 769-779. doi:10.1007/s11663-003-0083-0

Manso, J. M., Gonzalez, J. J. and Polanco, J. A. (2004). Electric arc furnace slag in concrete. Journal of Materials in Civil Engineering, 16(6), 639-645. doi:10.1061/(ASCE)0899-1561(2004)16:6(639)

Manso, J. M., Polanco, J. A., Losañez, M. and González, J. J. (2006). Durability of concrete made with EAF slag as aggregate. Cement and Concrete Composites, 28(6), 528-534. doi:10.1016/j.cemconcomp.2006.02.008

Motz, H. and Geiseler, J. (2001). Products of steel slags an opportunity to save natural resources. Waste Management, 21(3), 285-293.

Santamaría, A., Orbe, A., Losañez, M. M., Skaf, M., Ortega-Lopez, V. and González, J. J. (2017). Self-compacting concrete incorporating electric arc-furnace steelmaking slag as aggregate. Materials and Design, 115, 179-193. doi:10.1016/j.matdes.2016.11.048 